\title{
Low dose aspirin therapy and renal function in elderly patients
}

\author{
This article was published in the following Dove Press journal: \\ International Journal of General Medicine \\ 9 January 2013 \\ Number of times this article has been viewed
}

\author{
Patience Olayinka Akinwusi ${ }^{1,2}$ \\ Rotimi Oluyombo² \\ Paul Sunday Ogunro ${ }^{3}$ \\ Adetunji Oladeni Adeniji ${ }^{4}$ \\ Oluyomi Olusola Okunola ${ }^{5}$ \\ Olugbenga Edward Ayodele ${ }^{2}$ \\ 'Department of Medicine, Osun \\ State University, Osogbo, Osun State, \\ Nigeria; ${ }^{2}$ Department of Medicine, \\ LAUTECH Teaching Hospital, Osogbo, \\ Osun State, Nigeria; ${ }^{3}$ Department \\ of Chemical Pathology, LAUTECH \\ Teaching Hospital, Osogbo, Osun \\ State, Nigeria; ${ }^{4}$ Department of \\ Obstetrics and Gynecology, \\ LAUTECH Teaching Hospital, Osogbo, \\ Osun State, Nigeria; ${ }^{5}$ Department \\ of Medicine, Obafemi Awolowo \\ University, Ile-Ife, Osun State, Nigeria
}

Correspondence: Patience Olayinka Akinwusi

Department of Medicine, College of Health Sciences, Osun State University, Oke-Baale, PMB 4494, Osogbo,

Osun State, Nigeria

Tel +23480 372I 945I

Email pat.akinwusi@uniosun.edu.ng
Purpose: To determine whether low dose aspirin has any deleterious effects on renal function in elderly patients.

Methods: We conducted a prospective pilot study of 30 Nigerians older than 60 years with various chronic ailments necessitating the use of low dose aspirin. Patients gave their consent, and institutional ethical clearance was obtained. Each patient's baseline samples at enrolment (before commencing aspirin use) served as a control, and subsequent weekly samples were compared. The weekly mean of each parameter was calculated, and the differences of means from baseline were determined, and values were compared for statistical differences with the Statistical Package for the Social Sciences, version 16.

Results: We found that a majority of patients (86.67\%) had basal renal functions at chronic kidney disease stages 1 and 2 . When compared with the corresponding baseline parameters, the mean weekly serum and urinary electrolytes, urea, creatinine, and uric acid parameters did not change, and the $P$-value did not show any statistical significance. However, there was positive statistical significance for the creatinine clearance $(P=0.025)$. Also, unlike in previous studies, anemia and hypoalbuminemia did not affect the renal function parameters.

Conclusion: This study did not show any deleterious effects with short-term, low dose (75 mg daily) aspirin use on kidney functions in elderly patients. However, caution should be exercised when dealing with patients in renal stages $3-5$ and the very elderly, aged $\geq 80$ years.

Keywords: elderly, low dose aspirin, renal functions

\section{Introduction}

Aspirin is easily available across the counter in most countries including the developing countries such as Nigeria. When indicated, it is a common practice to maintain patients on long-term, low dose aspirin use without assessing their renal status prior to initiation of treatment.

Low dose aspirin is increasingly being used as an antiplatelet to prevent thrombosis and other fatal cardiovascular outcomes in at-risk patients. ${ }^{1,2}$ Elderly patients not only form the majority of these at-risk patients, ${ }^{1,2}$ but they also readily succumb to the deleterious effects of aspirin on renal function. ${ }^{3-5}$

Various studies assessing the elderly among Caucasian populations have shown that 1-2 weeks of low dose aspirin use (75 mg-325 mg/day) caused significant decreases in both creatinine clearance $(\mathrm{CrCl})$ and uric acid clearance, as well as elevations in serum creatinine and uric acid. ${ }^{6-8}$ These parameters improved upon withdrawal of the drug, but the decline in the glomerular filtration rate persisted 3 weeks posttreatment. ${ }^{6-8}$ 
Thus, long-term aspirin administration may have clinically important deleterious effects on renal function. ${ }^{8}$

This study was therefore undertaken as a pilot study to ascertain whether low dose aspirin compromises renal function amongst Nigerians, and if so, to alert practicing physicians on the need to show discretion when prescribing this drug.

\section{Methods}

This study employed a cohort of 30 elderly patients (age $\geq 60$ years) from the Ladoke Akintola University of Technology Teaching Hospital, southwest Nigeria, and was comprised of 16 male and 14 female patients at the commencement of the study. The United Nations definition of an elderly person was used. ${ }^{9}$ Ladoke Akintola University of Technology Teaching Hospital ethical clearance was obtained, and all of the patients gave informed consent (verbal and written). The patients were those enrolled in long-term care, as well as new patients with various medical conditions necessitating the use of low dose aspirin that were in stable clinical conditions throughout the study. Each patient was followed up for a period of 6 weeks with a weekly clinic appointment.

Excluded from the study were patients with a history of active peptic ulcer, gastrointestinal bleeding, chronic liver diseases, hyperuricemia, serum creatinine $>1.5 \mathrm{mg} / \mathrm{dL}$ (132.6 $\mu \mathrm{mol} / \mathrm{L})$, a significant history of alcohol consumption, or recent use of anticoagulants, aspirin, or nonsteroidal antiinflammatory drugs. Patients were put on moderate protein intake $(0.6-0.8 / \mathrm{kg}$ of body weight) with the assistance of dieticians a week prior to the commencement of the study; this was maintained throughout the 6-week study. The status quo was maintained for all other drugs (dosages unchanged), including diuretics. Patients who dropped out of the study were included in the calculations until their exit. The study took place over a period of 12 months from January 2008 to December 2008.

Blood and 24-hour urine were collected before the first dose of aspirin. Aspirin at a dose of $75 \mathrm{mg}$ /day was administered orally after breakfast for 2 weeks and then stopped. Follow-up then continued for a further 4 weeks.

Blood and 24-hour urine were collected at the end of each treatment week, as well as after each of the four consecutive weeks follow-up visits. Subjects were taught how to collect their 24-hour urine prior to their clinic day when the blood would be collected. After an overnight fast, $10 \mathrm{~mL}$ of venous blood was collected at the ante cubital fossa in the sitting position without stasis; $5 \mathrm{~mL}$ of the blood was put into lithium heparinized bottle, and the remaining $5 \mathrm{~mL}$ were put into a plain bottle. Serum was obtained after clotting, centrifuged at $3500 \mathrm{rpm}$ for 10 minutes, and immediately stored at $-20^{\circ} \mathrm{C}$ until they were analyzed. Sodium and potassium were analyzed using flame emission photometry (Corning 410c photometer CIBA Corning Analytical, Halstead Essex, UK), bicarbonate by method of back titration, and chloride by rapid precision method. ${ }^{10}$

Serum creatinine, blood urea nitrogen, uric acid, and albumin were analyzed by standard methods of Jaffes reaction, ${ }^{11}$ modified Berthelot, ${ }^{12}$ enzymatic urease, ${ }^{13}$ and bromocresol green, ${ }^{14}$ respectively, using the Humalyzer 2000 Chemistry Analyzer (HUMAN Gesellschaft für Biochemica und Diagnostica mbH, Wiesbaden, Germany). Urinary $\mathrm{CrCl}$ and uric acid clearance were evaluated by 24-hour urine collection for $\mathrm{CrCl}$ and uric acid clearances.

The small sample size is a limitation of this study.

\section{Statistics}

Pro forma data entry and statistical analysis were performed. Each patient's baseline samples at enrolment (before commencing aspirin) served as the control, and subsequent weekly samples were compared. The weekly mean of the samples was calculated, and the difference of means from the baseline mean were determined and compared for statistical significance $(P \leq 0.05)$ using the Statistical Package for the Social Sciences version 16 software (SPSS Inc, Chicago, IL, USA).

\section{Results}

A total of 30 black Nigerians participated in this preliminary study. There were 14 (46.7\%) females and $16(53.3 \%)$ males with age range between $60-88$ years and mean ages of 68.44 years $( \pm 8.16)$ and 70.43 years $( \pm 9.09)$ for males and females, respectively.

Table 1 shows the clinical data of the patients. Twelve $(40 \%)$ of the patients had more than one diagnosis. Systemic hypertension was the most common diagnosis, accounting for $18(60.0 \%)$ of cases. Hypertension and diabetes mellitus coexisted in seven $(23.3 \%)$ of the study participants.

Table 2 shows the stages of renal function based on the National Kidney Function/DOQI guideline: 86.67\% exhibited their basal renal function in stages 1 and 2 based on $\mathrm{CrCl}$.

Figures 1-8 show the weekly assessment of the effects of low dose aspirin on renal functions among the patients in graphical form. The mean of each weekly parameter was compared with the corresponding baseline parameter, as well as with the $P$-value displayed on the graph. The $P$-value for all these weekly parameters did not show statistical significance except for the $\mathrm{CrCl}$ (Figure $8 ; P=0.025$ ). The $\mathrm{CrCl}$ 
Table I Clinical data

\begin{tabular}{|c|c|c|}
\hline & Number of patients & $\%$ \\
\hline \multicolumn{3}{|l|}{ Diagnosis* } \\
\hline Systemic hypertension & 18 & 60.0 \\
\hline Congestive cardiac failure & 3 & 10.0 \\
\hline Diabetes mellitus & 6 & 20.0 \\
\hline Peripheral artery disease & 5 & 16.7 \\
\hline Carotid aneurysm & I & 3.3 \\
\hline Ischemic cardiovascular disease & 2 & 6.7 \\
\hline Obesity & 2 & 6.7 \\
\hline Parkinson's disease & I & 3.3 \\
\hline Background COPD & 3 & 10 \\
\hline \multicolumn{3}{|l|}{ Drugs** } \\
\hline Diuretics & 28 & 93.3 \\
\hline $\begin{array}{l}\text { Antibenign prostatic hypertrophy } \\
\text { (and receptor blocker) }\end{array}$ & 1 & 3.3 \\
\hline \multicolumn{3}{|l|}{ Antihypertensives } \\
\hline $\begin{array}{l}\text { Excluding thiazides and angiotensin } \\
\text { converting enzyme inhibitors }\end{array}$ & 17 & 56.7 \\
\hline Digoxin & 2 & 6.7 \\
\hline Oral hypoglycemic agents & 5 & 16.7 \\
\hline Insulin & 2 & 6.7 \\
\hline $\begin{array}{l}\text { Angiotensin converting enzyme } \\
\text { inhibitors }\end{array}$ & 12 & 40.0 \\
\hline
\end{tabular}

Notes: *Some patients had multiple diagnoses; **all the patients were on multiple drugs.

Abbreviation: COPD, chronic obstructive pulmonary disease.

reduced at week 2 , and then increased at week 3 , pleateauing before gradually returning to baseline at the sixth week.

The mean hemoglobin was $12.3 \pm 5.6 \mathrm{~g} / \mathrm{dL}$ with a range of $7.3-15.0 \mathrm{~g} / \mathrm{dL}$.

\section{Discussion}

This study did not show any significant deterioration effects in renal function in the geriatric patients studied, during or after a 2-week administration of low dose $(75 \mathrm{mg})$ aspirin in all of the investigated parameters, as shown in Figures 1-8. This is not in accordance with previously published studies that were conducted outside Nigeria. ${ }^{3,6-8}$

Previous studies have shown that low dose aspirin (75-325 mg) in the elderly, even on a short-term basis, had significant effects on renal tubular function..$^{6-8}$ Furthermore, one of the studies showed that even at the lowest dose of

Table 2 NKF/DOQI classification of patients in this study

\begin{tabular}{lll}
\hline Stage & GFR $(\mathbf{m L} / \mathbf{m i n})$ & $\mathbf{C r C l}(\%)$ \\
\hline 1 & $\geq 90$ & $17(56.7)$ \\
2 & $60-89$ & $9(30.0)$ \\
3 & $30-59$ & $4(13.3)$ \\
4 & $15-29$ & - \\
5 & $<15$ & - \\
\hline
\end{tabular}

Abbreviations: NKF, National Kidney Foundation; DOQI, Dialysis Outcome Quality Initiative; GFR, glomerular filtration rate; $\mathrm{CrCl}$, creatinine clearance. aspirin $(75 \mathrm{mg})$ per day, administered for 1 week, the uric acid clearance and $\mathrm{CrCl}$ reduced. Only the uric acid clearance returned to the baseline 1 week after the discontinuation of aspirin. $^{6}$

The disparity from previous studies noticed in this study may be due to the better baseline renal functions of our patients.

As shown in Table 2 , more than $85 \%$ of the study subjects had their basal renal function $(\mathrm{CrCl}, 86.7 \%)$ in stages 1 and 2 of the American National Kidney Foundation criteria, whereas only about $50 \%(\mathrm{CrCl}, 57 \%)$ of the patients in the Segal et $a l^{8}$ study had theirs in the later stages.

Similarly, the study subjects were younger (age range, $60-88$ years; overall mean of $69.40 \pm 8.48$ years) with only four $(13.33 \%)$ that were considered to be in the very elderly age group ( $\geq 80$ years). Previous studies used older patients with a mean age of $80 \pm 9$ years, ${ }^{8}$ and an average age of 81 years. $^{7}$ Of note, renal functions depreciate with age; ${ }^{15,16}$ hence, the basal renal functions of the patients in this study were better than those of other studies. This might have attenuated the renal effects of low dose aspirin.

Only two $(6.67 \%)$ of the patients in this study were anemic. This is in keeping with the stage of their renal functions. Anemia in chronic kidney disease becomes progressively pronounced from stage 3 onward.${ }^{17}$ Similarly, only 14 (46.7\%) of the patients had hypoalbuminemia.

Previous studies have shown that hypoalbuminemia and anemia potentiate the deleterious effects of low dose aspirin on renal function. ${ }^{6,8}$ This current study did not conform to this. This may be due to the very small number of our study patients having either hypoalbuminemia or anemia.

Previous studies have also shown significantly lower $\mathrm{CrCl}$ on a concomitant low dose aspirin-diuretic combination. ${ }^{18,19}$ Our finding differs from this observation, as $93.3 \%$ of the patients in this study were on this combination, yet there was no significant lowering of the $\mathrm{CrCl}$. Instead, in Figure 8 we observed positive statistical significance $(P=0.025)$ in the $\mathrm{CrCl}$ parameter. The $\mathrm{CrCl}$ at week 2 reduced and increased by the third week, plateauing before gradually returning to baseline at the sixth week. We are of the opinion that the multiple drugs aimed at ameliorating the various comorbid conditions in the patients of our study might have acted in synergy with the low dose aspirin to give this favorable increase in $\mathrm{CrCl}$ during the study. A larger sample with the application of more advanced statistics is advocated in order to provide a more concrete explanation for this observation. The small sample size is a limitation of this study. 


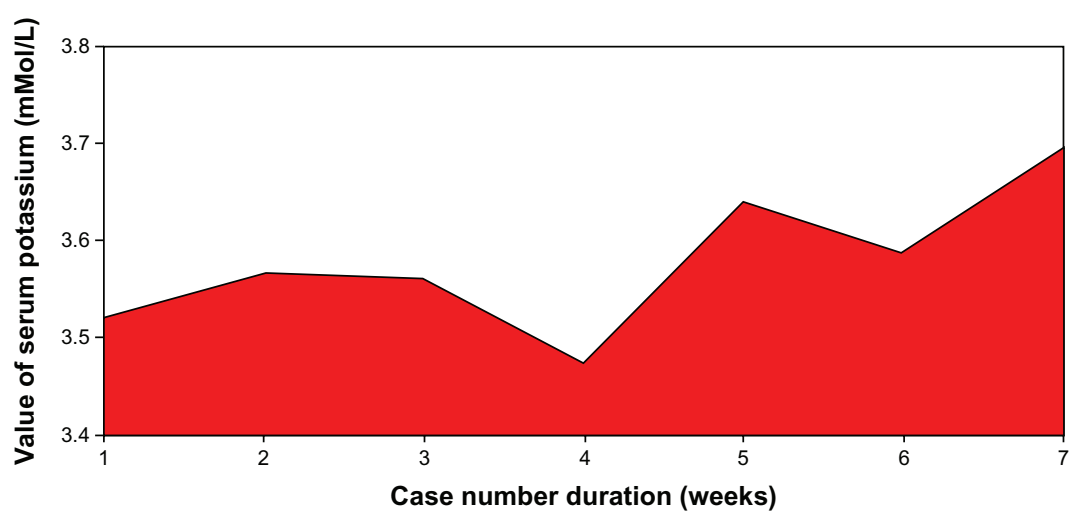

Figure I Pattern of serum potassium levels of patients on low dose aspirin. Note: $\mathrm{F}=0.53 ; P=0.784$.

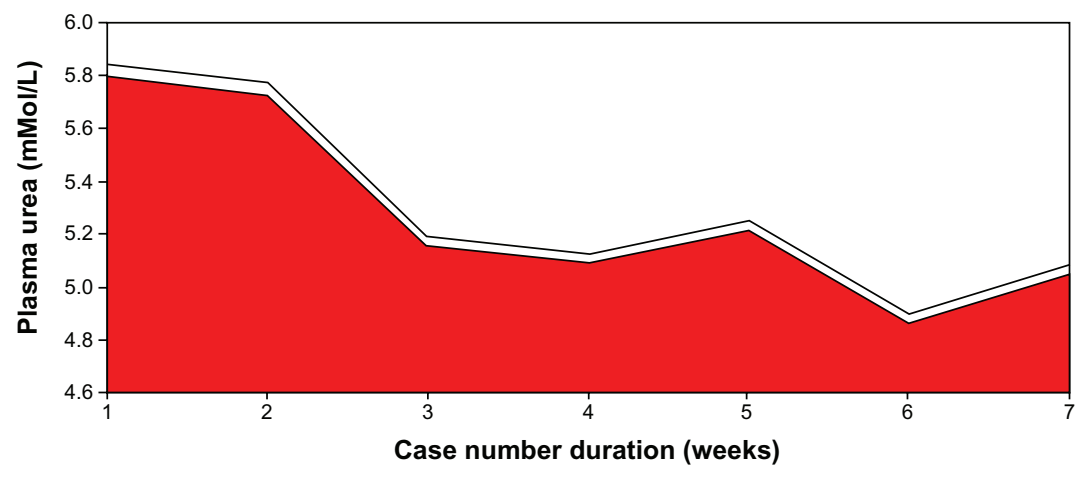

Figure 2 Pattern of plasma urea of patients on low dose aspirin. Note: $\mathrm{F}=0.63 ; P=0.709$.

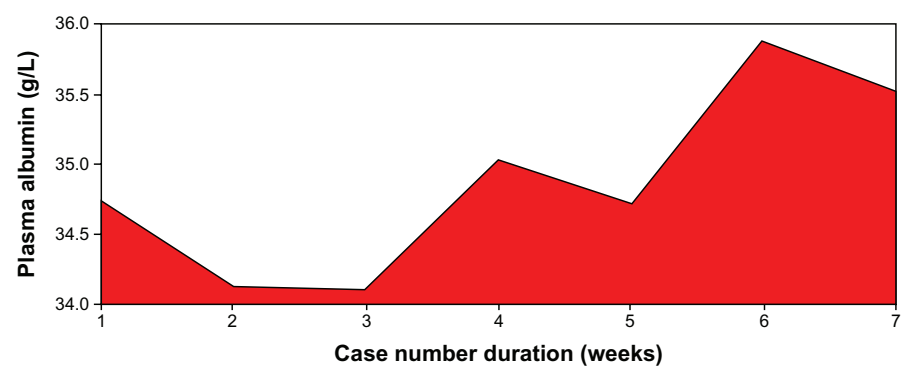

Figure 3 Pattern of serum albumin of patients on low dose aspirin. Note: $\mathrm{F}=0.19 ; P=0.978$.

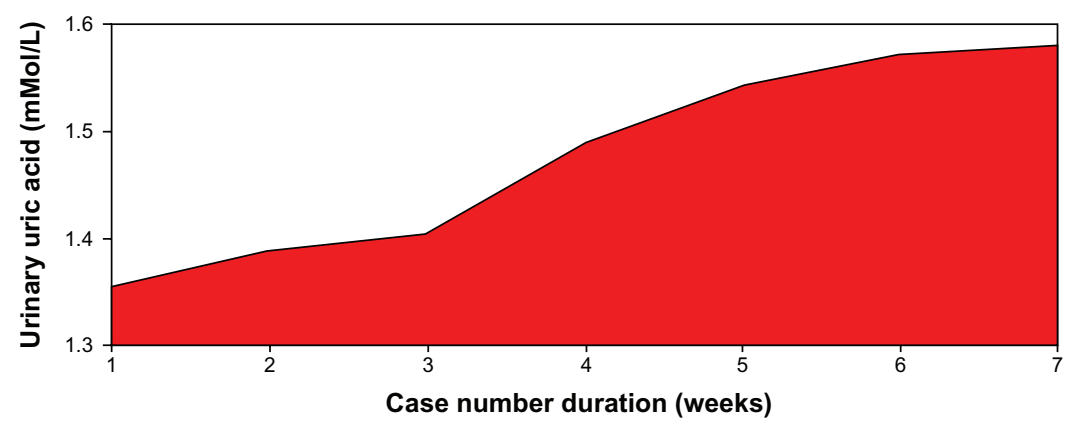

Figure 4 Pattern of urinary uric acid levels of patients on low dose aspirin. Note: $F=0.50 ; P=0.8 \mathrm{I}$. 


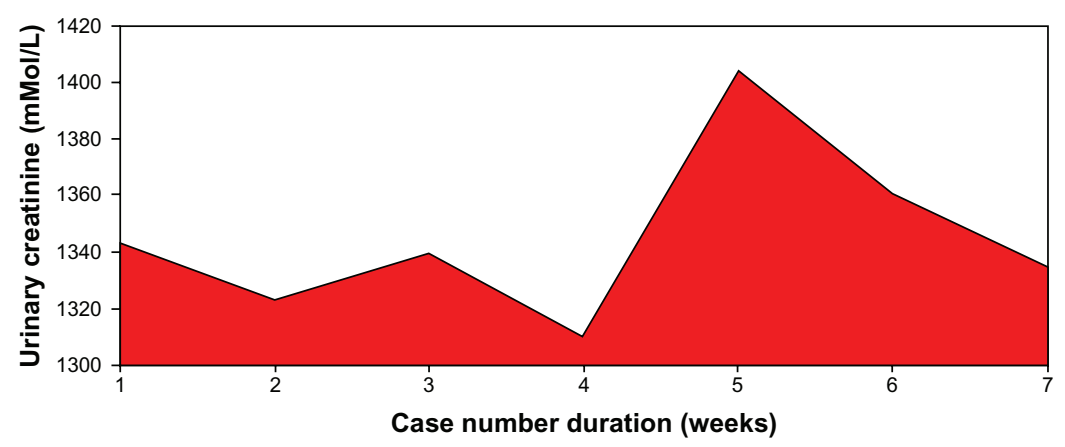

Figure 5 Pattern of urinary creatinine in patients on low dose aspirin.

Note: $\mathrm{F}=0.35 ; P=0.911$.

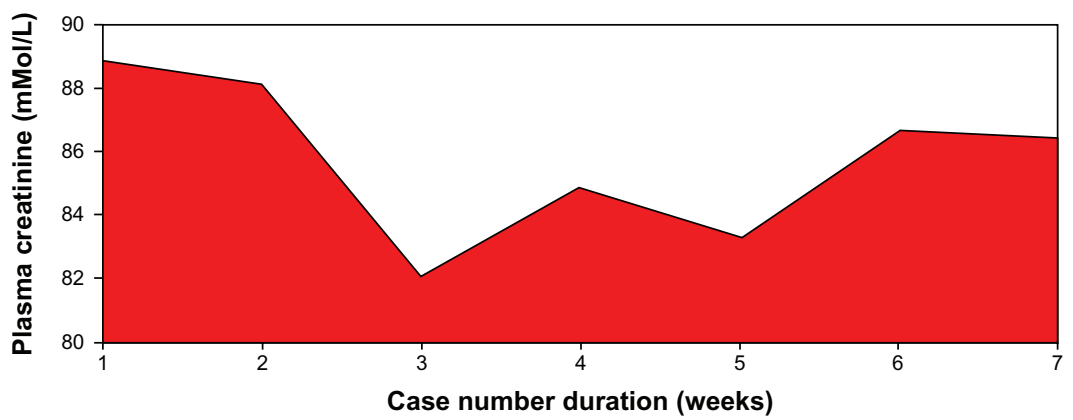

Figure 6 Pattern of plasma creatinine levels of patients on low dose aspirin.

Note: $F=0.60 ; P=0.731$.

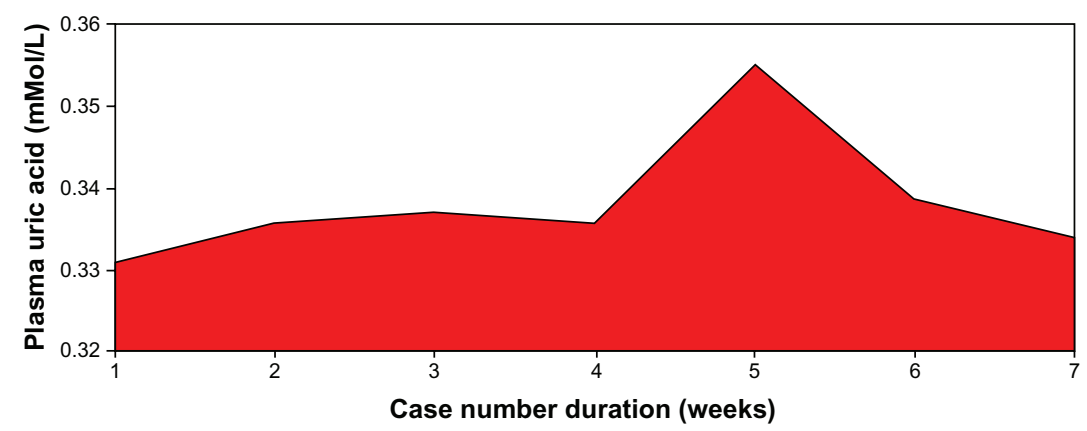

Figure 7 Pattern of plasma uric acid levels of patients on low dose aspirin. Note: $\mathrm{F}=0.33 ; P=0.921$.

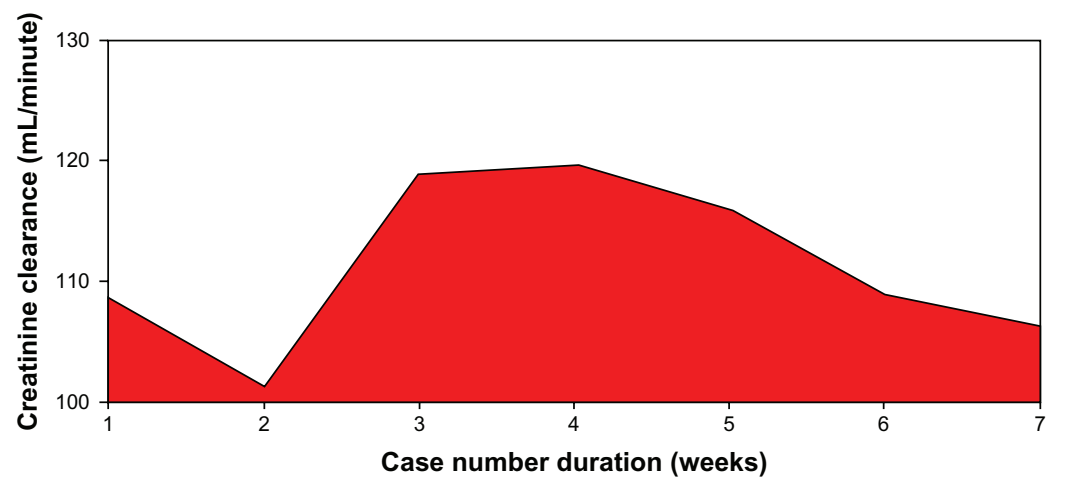

Figure 8 Pattern of creatinine clearance of patients on low dose aspirin. Note: $\mathrm{F}=2.48 ; P=0.025$. 
The decision to put an elderly patient on low dose aspirin should be based on the basal renal functions and the age of the patient. Caution should be exercised when dealing with those in renal stages $3-5$, and when dealing with the very elderly (age $\geq 80$ years). We also suggest that the $75 \mathrm{mg}$ dose of aspirin should be retained as the antiplatelet of choice in the elderly in developing countries.

\section{Conclusion}

This study did not show any deleterious effects of short-term, low dose aspirin $(75 \mathrm{mg})$ use on the renal function of elderly patients. This 6-week study was cumbersome for most of the patients, and this precluded the participation of a lot of eligible geriatric patients. Not all of the 30 patients completed the study, but their data for the period of participation were included in the analysis.

The small sample size combined with the tasking nature of the study that was conducted in a peculiar setting might have affected the results. We suggest that more studies be conducted in our own environment with a larger sample size, and possibly in a center with a predominant geriatric population.

\section{Acknowledgments}

We are grateful to Mr Adeola Ayileka and Mr Peter Awosanmi of the malaria research unit of the hospital for assistance rendered during the period of sample collection and data entry. The assistance rendered by Mr Nureni Agbaje of the Chemical Pathology Department is also appreciated. The study was funded by the authors.

\section{Disclosure}

The authors report no conflicts of interest in this work.

\section{References}

1. Ancheta JI, Reding MJ. Stroke diagnosis and management: a multidisciplinary effort. In: Hazzard WR, Blass JP, Ettinger WH Jr, Halter JB, Ouslander JG, editors. Principles of Geriatric Medicine and Gerontology, 4th ed. New York: McGraw-Hill; 1999:124.

2. Gurwitz JH, Gore JM, Goldberg RJ, Rubison M, Chandra N, Rogers WJ. Recent age-related trends in the use of thrombolytic therapy in patients who have had acute myocardial infarction. National Registry of Myocardial Infarction. Ann Intern Med. 1996;124(3):283-291.
3. Silagy CA, McNeil JJ, Donnan GA, Tonkin AM, Worsam B, Campion K. Adverse effects of low-dose aspirin in a healthy elderly population. Clin Pharmacol Ther. 1993;54(1):84-89.

4. Krumholz HM, Radford MJ, Ellerbeck EF, et al. Aspirin in the treatment of acute myocardial infarction in elderly Medicare beneficiaries. Circulation. 1995;92(10):2841-2847.

5. Gurwitz JH, Avorn J, Ross-Degnan D, Lipsitz LA. Nonsteroidal anti-inflammatory drug-associated azotemia in the very old. JAMA. 1990;264(4):471-475.

6. Caspi D, Lubart E, Graff E, Habot B, Yaron M, Segal R. The effect of mini-dose aspirin on renal function and uric acid handling in elderly patients. Arthritis Rheum. 2000;43(1):103-108.

7. Segal R, Lubart E, Leibovitz A, et al. Early and late effects of lowdose aspirin on renal function in elderly patients. Am J Med. 2003; 115(6):462-466.

8. Segal R, Lubart E, Leibovitz A, Iaina A, Caspi D. Renal effects of low dose aspirin in elderly patients. Isr Med Assoc J. 2006;8(10):679-682.

9. World Health Organization [webpage on the Internet]. Health statistics and health information systems. Definition of an older or elderly person. Proposed working definition of an older person in Africa for the MDS project. Geneva: World Health Organization. Available from: http://www.who.int/healthinfo/survey/ageingdefnolder/en/index.html. Accessed January 10, 2012.

10. Malmstadt HV, Winefordner JD. Determination of chloride in blood serum, plasma, or other biologic fluids by a new rapid precision method. Clin Chem. 1959;5(4):284-296.

11. Haeckel R. Simplified determinations of the "true" creatinine concentration in serum and urine. J Clin Chem Clin Biochem. 1980;18(7): 385-394.

12. Fawcett JK, Scott JE. A rapid and precise method for the determination of urea. J Clin Pathol. 1960;13:156-159.

13. Fossati P, Prencipe L, Berti G. Uses of 3,5-dichloro-2-hydroxybenzensulfonic acid/4-aminophenazone chromogenic system in direct enzymatic assay of uric acid in serum and urine. Clin Chem. 1980;26(2): 227-231.

14. Doumas BT, Watson WA, Biggs HC. Albumin standards and the measurement of serum albumin with bromcresol green. Cin Chim Acta. 1971;31(1):87-96.

15. Schramm A, Jenett M, Gerhardt KH. Changes in kidney function and morphology in the aged. Z Gerontol. 1981;14(5):354-369. German.

16. Godin M, Moulin B, Etienne I, Fillastre JP. Renal aging in man. Presse Med. 1992;21(26):1246-1248. French.

17. Astor BC, Muntner P, Levin A, Eustace JA, Coresh J. Association of kidney function and anemia: the Third National Health and Nutrition Examination Survey (1988-1994). Arch Intern Med. 2002;162(12): 1401-1408.

18. Sweileh WM. Potential adverse effects of a low-dose aspirindiuretic combination on kidney function. Int J Clin Pharmacol Ther. 2007;45(11):601-605.

19. Juhlin I, Jönsson BA, Höglund P. Renal effects of aspirin are clearly dose-dependent and are of clinical importance from a dose of $160 \mathrm{mg}$. Eur J Heart Fail. 2008;10(9):892-898.
International Journal of General Medicine

\section{Publish your work in this journal}

The International Journal of General Medicine is an international, peer-reviewed open-access journal that focuses on general and internal medicine, pathogenesis, epidemiology, diagnosis, monitoring and treatment protocols. The journal is characterized by the rapid reporting of reviews, original research and clinical studies across all disease areas.

\section{Dovepress}

A key focus is the elucidation of disease processes and management protocols resulting in improved outcomes for the patient.The manuscript management system is completely online and includes a very quick and fair peer-review system. Visit http://www.dovepress.com/ testimonials.php to read real quotes from published authors. 